\title{
Commentary: Have mitral valve simulators made it to reality?
}

Giye Choe, $M D,{ }^{a}$ and Frederick A. Tibayan, $\mathrm{MD}^{\mathrm{b}}$

\footnotetext{
From ${ }^{\text {aThoracic }}$ Service, Department of Surgery, Memorial Sloan-Kettering Cancer Center, New York, NY; and ${ }^{\mathrm{b}}$ Division of Cardiothoracic Surgery, Department of Surgery, Oregon Health \& Science University, Portland, Ore.

Disclosures: Authors have nothing to disclose with regard to commercial support.

Received for publication Sept 21, 2018; accepted for publication Sept 21, 2018; available ahead of print Nov 7 , 2018.

Address for reprints: Frederick A. Tibayan, MD, 3181 SW Sam Jackson Park Rd, Mail Code L353, Portland, OR 97239 (E-mail: tibayan@ohsu.edu).

J Thorac Cardiovasc Surg 2019;157:1576

$0022-5223 / \$ 36.00$

Copyright $\subset 2018$ by The American Association for Thoracic Surgery

https://doi.org/10.1016/j.jtcvs.2018.09.064
}

The past decade has seen tremendous growth in the role of simulation in cardiothoracic surgery training. Simulators may have a role in teaching and shortening the learning curve associated with complex cardiothoracic procedures. ${ }^{1}$ In parallel, minimally invasive mitral valve surgery (MIMVS) is increasingly accepted as a feasible and efficacious approach for patients with mitral valve disease. What has been lacking, especially in the field of MIMVS, is a high-fidelity simulator that provides objective feedback on components of the operation.

Nia and colleagues ${ }^{2}$ report the development of a mitral valve surgery simulator that bridges that gap and provides real-time validated measurements of suture width and depth in a silicone valve using multiple cameras and a novel optical analysis algorithm. The model thorax is designed for a variety of mitral approaches, including endoscopic with an access port in the fourth intercostal space, robotic with 3 trocar-like ports, and full sternotomy. Surgeons testing the simulator found the look and feel realistic, and agreed it is a good tool for training MIMVS.

Such an innovative technology may be useful for skills assessment and certification, but applications toward deliberate practice for trainees new to MIMVS are even more exciting. Gamification-using principles of game design to make education more engaging ${ }^{3}$ - is more and more prevalent in surgical training. ${ }^{4}$ Ideally, this simulator could provide real-time, objective scoring on suture placement in progressively more challenging valve models, intrinsically (or extrinsically) motivating continued practice and improvement.

Before such applications become reality, more validation is required. Although simulation has been shown to improve comfort level in operating rooms, ${ }^{5}$ no data yet exist on whether this translates into safer, more reproducible technique in clinical settings. To take full advantage of the feedback system, learners need standards and tolerances for can be measured.

\section{References} Surg. 2017;153:1530-40. 1567-74.

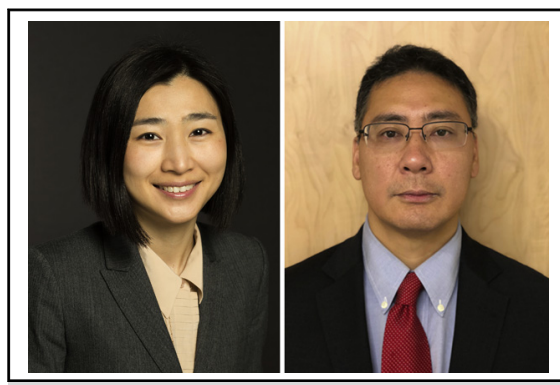

Giye Choe, MD, and Frederick A. Tibayan, MD

Central Message

High-fidelity mitral simulation with objective feedback shows promise in developing the skills needed to perform minimally invasive mitral surgery, but validation is still needed.

See Article page 1567.

suture width and depth against which their performances

The authors' contribution ${ }^{2}$ represents an important advance in the fields of MIMVS and simulation. Simulators may dramatically aid skill acquisition; however, they will make teachers more, not less important. In my earliest and most vivid cardiothoracic simulation memory, a mentor took me through a root replacement on a porcine heart, constantly providing context and guidance. Trainees will always need expert mentors to teach them where (and when) to place the stitches.

1. Yoo SJ, Spray T, Austin EH, Yun TJ, van Arsdell GS. Hands-on surgical training of congenital heart surgery using 3-dimensional print models. J Thorac Cardiovasc

2. Nia PS, Daemen JHT, Maessen JG. Development of a high-fidelity minimally invasive mitral valve surgery simulator. J Thorac Cardiovasc Surg. 2019;157:

3. Gamification - how the principles of play apply to real life. Available at: https:// www.youtube.com/watch? $\mathrm{v}=1 \mathrm{dLK} 9 \mathrm{MW}-9 \mathrm{~s} Y \& \mathrm{t}=3 \mathrm{~s} \&$ list=PLhyKYa0YJ_5CGkK 6JpIagshOH0k4hi3vD\&index=7. Accessed September 17, 2018.

4. Mokadam NA, Lee R, Vaporciyan AA, Walker JD, Cerfolio RJ, Hermsen JL, et al. Gamification in thoracic surgical education: using competition to fuel performance. J Thorac Cardiovasc Surg. 2015;150:1052-8.

5. Mokadam NA, Fann JI, Hicks GL, Nesbitt JC, Burkhart HM, Conte JV, et al. Experience with the cardiac surgery simulation curriculum: results of the resident and faculty survey. Ann Thorac Surg. 2017;103:322-8. 